\title{
HEMATOPOIETIC PROGENITOR CELL CONTENT OF VERTEBRAL BODY MARROW USED FOR COMBINED SOLID ORGAN AND BONE MARROW TRANSPLANTATION ${ }^{1}$
}

\author{
Witold B. Rybka, ${ }^{2,3,4}$ Paulo A. Fontes, ${ }^{5,6}$ Abdul S. Rao, ${ }^{5,6,7}$ Alan Winkelstein, ${ }^{2,4}$ \\ CAmillo Ricordi, ${ }^{8}$ Edward D. Ball, ${ }^{2,4}$ aNd Thomas E. STARzL ${ }^{5,6}$
}

Pittsburgh Transplantation Institute and Bone Marrow Transplant Program, Pittsburgh Cancer Institute; Departments of Medicine, Surgery, and Pathology, University of Pittsburgh Medical Center, Pittsburgh, Pennsylvania 15213; and the

Diabetes Research Institute, Miami, Florida 33136

\begin{abstract}
While cadaveric vertebral bodies (VB) have long been proposed as a suitable source of bone marrow (BM) for transplantation (BMT), they have rarely been used for this purpose. We have infused VB BM immediately following whole organ (WO) transplantation to augment donor cell chimerism. We quantified the hematopoietic progenitor cell (HPC) content of VB BM as well as BM obtained from the iliac crests (IC) of normal allogeneic donors (ALLO) and from patients with malignancy undergoing autologous marrow harvest (AUTO). Patients undergoing WO/BM transplantation also had AUTO BM harvested in the event that subsequent lymphohematopoietic reconstitution was required. Twenty-four VB BM, 24 IC BM-ALLO, 31 IC AUTO, and 24 IC WO-AUTO were harvested. VB BM was tested 12 to $72 \mathrm{hr}$ after procurement and infused after completion of WO grafting. IC BM was tested and then used or cryopreserved immediately. HPC were quantified by clonal assay measuring CFU-GM, BFU-E, and CFU-GEMM, and by flow cytometry for CD34 ${ }^{+}$ progenitor cells. On an average, $9 \mathrm{VB}$ were processed during each harvest, and despite an extended processing time the number of viable nucleated cells obtained was significantly higher than that from IC. Furthermore, by HPC content, VB BM was equivalent to IC $B M$, which is routinely used for BMT. We conclude that VB BM is a clinically valuable source of BM for allogeneic transplantation.
\end{abstract}

Transplantation of any organ results in the migration of bone marrow-derived leukocytes from the donor into the recipient, where they have been shown to persist indefinitely (1-5). We have postulated that this is the seminal explanation for allograft acceptance with such migration being required as the first stage in the development of donor-specific nonreactivity (tolerance) (1-5). This phenomenon was augmented in 18 patients by infusing donor bone marrow cells at

\footnotetext{
1 This work was partially supported by NIH Grant DK 29961.

${ }^{2}$ Bone Marrow Transplant Program, Pittsburgh Cancer Institute.

${ }^{3}$ Address reprint requests to Witold B. Rybka, M.D., University of Pittsburgh Medical Center, 200 Lothrop St., Pittsburgh, PA 15213.

${ }^{4}$ Department of Medicine, University of Pittsburgh Medical Center.

${ }^{5}$ Cell Transplantation Laboratory, Pittsburgh Transplantation Institute.

${ }^{6}$ Department of Surgery, University of Pittsburgh Medical Center.

${ }^{7}$ Department of Pathology, University of Pittsburgh Medical Center.

8 The Diabetes Research Institute.
}

the time of whole organ transplantation (6). In the first 17 analyzable patients receiving perioperative infusion of $3 \times 10^{8}$ unmodified donor marrow cells $/ \mathrm{kg}$ at the time of organ grafting, persistent multilineage leukocyte chimerism was demonstrated for up to 16 months following transplantation. Donor specific hyporeactivity was also demonstrable with in vitro testing in the majority of these recipients as early as 50 days posttransplantation.

Iliac crests are routinely used as a source of bone marrow (BM)* from living donors (7). However, for these augmentation studies, VB BM was used, as a favorable alternative source with the advantage of less peripheral blood contamination $(8,9)$. In addition, excision of vertebral bodies can be performed rapidly allowing subsequent extraction and processing of the marrow. This study presents a comparison of hematopoietic clonogenic progenitors present in VB BM obtained for combined marrow and whole organ transplantation with that from iliac crest of normal allogeneic donors and from patients with malignancy, undergoing autologous marrow harvest.

The measurement of the engraftment potential of human marrow has been elusive. However, surrogate markers for hematopoietic stem cells have been used extensively to determine the suitability of bone marrow for transplantation. Clinical utility has been demonstrated in the measurement of the nucleated cell dose with optimal engraftment at levels of $3 \times 10^{8}$ nucleated marrow cells $/ \mathrm{kg}$ of recipient body weight (10). Additionally, the levels of CD34 ${ }^{+}$cells (11) and that of the clonal hematopoietic progenitors, (CFU-GM, BFU-E, and CFU-GEMM), have also been used to define autologous marrow collections (12-15). These parameters have been used in this study to compare different sources of marrow in an attempt to ascertain their utility in clinical bone marrow transplantation.

\section{MATERIALS AND METHODS}

Study population. The thoracolumbar vertebral column (VC) was harvested from 24 cadaveric organ donors, yielding an average of 9 VB per donor. The marrow obtained was subsequently infused perioperatively into $18 \mathrm{ABO}$-matched recipients undergoing whole organ transplantation. Iliac crest marrow was harvested from 79 adult

* Abbreviations: BFU-E, burst forming unit-erythroid; BM, bone marrow; BMT, bone marrow transplantation; CFU-GEMM, CFUgranulocyte, erythrocyte, megakaryocyte, macrophage; CFU-GM, CFU-granulocyte macrophage; HPC, hematopoietic progenitor cell; IC, iliac crests; PBS, phosphate-buffered saline; VB, cadaveric vertebral bodies. 
living donors for subsequent marrow transplantation. Twenty-four of these harvests were from normal donors for related or unrelated matched allogeneic marrow transplantation. Thirty-two harvests were from patients undergoing chemotherapy for the treatment of malignancy for subsequent autologous transplantation, and 24 harvests were from recipients of combined organ and bone marrow transplantation. In the latter group, the marrow was harvested and cryopreserved in the event that subsequent lymphohematopoietic reconstitution was required. Informed consent was obtained in all cases. These investigations were approved by the Institutional Review Board for Biomedical Research of the University of Pittsburgh.

Vertebral body bone marrow (VB BM). The method for harvesting and processing marrow from VB has been described previously (16). Briefly, thoracolumbar VB were resected en bloc and transported to the University of Pittsburgh Medical Center at ambient temperature in "harvesting" medium containing Dulbecco's modified Eagle's medium (DMEM), supplemented with $2.5 \%$ human serum albumin, $5 \times 10^{3} \mathrm{U} / \mathrm{ml}$ Bacitracin, $5 \times 10^{4} \mathrm{U} / \mathrm{ml}$ Polymyxin, $10^{3} \mathrm{U} / \mathrm{ml}$ heparin, and 2 mM HEPES buffer (Gibco, Grand Island, NY). On arrival in the lab, VB were divided, the cancellous bone was chipped off, and the cells were released by gentle agitation into a "processing" medium, the constituents of which were the same as in the harvesting medium, with the exception of X-VIVO 10 (BioWhittaker, Walkersville, MD), which was substituted for DMEM. The released bone marrow cells from individual VB were then pooled, filtered, centrifuged at $300 \times \mathrm{g}$ for $11 \mathrm{~min}$, and placed in a "suspension" medium consisting of RPMI 1640, 2.5\% human serum albumin, $0.5 \mathrm{mg} / \mathrm{ml}$ gentamicin, $10 \mathrm{U} / \mathrm{ml}$ heparin, and $2 \mathrm{mM}$ HEPES buffer, and refrigerated until used. At 2 to $12 \mathrm{hr}$ after revascularization of the organ graft, $3 \times 10^{8}$ unmodified bone marrow cells $/ \mathrm{kg}$ were removed, centrifuged, and resuspended in $200 \mathrm{ml}$ of "suspension" solution, which was infused over $20 \mathrm{~min}$ via a central intravenous line into a nonconditioned recipient. BM was tested 12 to $72 \mathrm{hr}$ after procurement for progenitor cell assays and cell surface phenotype.

Iliac crest marrow. Marrow from the iliac crests was obtained by a standard technique (7). Briefly, this consisted of aspirating 10-15 $\mathrm{ml}$ of marrow/kg patient body weight by multiple percutaneous punctures of the iliac crest. The target for collection was 3-6 $\times 10^{8}$ nucleated cells $/ \mathrm{kg}$ recipient body weight. The aspirated marrow was then placed in Medium 199 (Gibco) anticoagulated with a final concentration of $10 \mathrm{U} / \mathrm{ml}$ of heparin, and it was either transfused immediately or cryopreserved. The marrow was tested within 2 to $6 \mathrm{hr}$ after procurement for clonogenic progenitor cells and for cell surface phenotype.

Nucleated cell counts. Nucleated cell counts were obtained on all samples using a Coulter ZM counter (Marietta, GA). In each preparation, the absolute number of cells was calculated from the product of the volume and the cell concentration.

Hematopoietic progenitor assays. The techniques used for clonal hematopoietic progenitor assays have been previously described (17). Briefly, $1.5 \times 10^{5}$ cells suspended in Iscove's methylcellulose supplemented with 5\% serum and PHA-LCM (Stem Cell Technologies,
Vancouver, BC), were plated in triplicate into 1-ml tissue culture plates and incubated in humidified $5 \% \mathrm{CO}_{2}$ at $37^{\circ} \mathrm{C}$ for 14 days. The plates were scored for colony-forming unit-granulocyte and macrophage (CFU-GM), burst forming unit-erythroid (BFU-E), and colonyforming unit-granulocyte, erythroid, megakaryocyte, and macrophage (CFU-GEMM) using an inverted microscope, and the mean number of colonies per $10^{5}$ nucleated cells was determined. Total CFU were defined as the sum of CFU-GM + BFU-E + CFU-GEMM.

Flow cytometry. The techniques used for $\mathrm{CD} 34^{+}$cell enumeration have been previously described (18). Briefly, whole cell preparations of marrow or blood were washed in PBS, centrifuged, and enumerated. The samples were then incubated for $60 \mathrm{~min}$ at room temperature with phycoerythrin (PE)-labeled monoclonal antibody cocktail: CD3 (T cells), CD11b (neutrophils), CD14 (monocytes), and CD19 (B cells) (Becton Dickinson, San Jose, CA). After washing $(\times 2)$ with PBS, the samples were incubated for an additional $1 \mathrm{hr}$ with fluorescein isothiocyanate (FITC)-conjugated monoclonal antibodies directed against human hematopoietic progenitor cells (CD34; 8G12 [Becton] and Q-Bend-10 [Gen Trak, Plymouth Meeting, PA]). At the end of this incubation, the cells were washed $(\times 2)$ in the PBS, erythrocytes were lysed with FACS lysing solution (Becton Dickinson), and the cells were subsequently fixed in $1 \%$ paraformaldehyde. Twenty-thousand events of each sample were acquired on a FACScan flow cytometer (Becton Dickinson) equipped with a $15 \mathrm{~mW}$, air-cooled, $488 \mathrm{~nm}$ argon-ion laser. Fluorescence data were displayed on a four-decade log scale and the analysis was performed with LYSYS II software (Becton Dickinson). Horizontal and vertical axes were determined by using the PE-conjugated cocktail and unstained U937 cells (ATCC, Rockville, MD) respectively. CD34 ${ }^{+}$cells lacking the phenotype of $\mathrm{T}$ and $\mathrm{B}$ cells, monocytes and neutrophils were defined using the preestablished quadrants. Debris was excluded by reference to $6-\mu$ beads (Calibrite, Becton Dickinson).

\section{RESULTS}

Cell yields. The marrow graft composition in terms of the numbers of nucleated cells, CD $34^{+}$cells, and total CFU is given in Table 1 for all four marrow sources. Quantitative differences between vertebral body and other sources of BM were significant in all categories with a $P$ value of $<0.001$. On an average, $9 \mathrm{VB}$ were harvested from each cadaveric donor, yielding $5.7 \pm 2.0 \times 10^{10}$ nucleated marrow cells/donor (a mean of $6.3 \times 10^{9}$ cells/VB), which was significantly higher than that obtained from any other source (Table 1). The unusually low number of cells recovered from iliac crests of patients undergoing whole organ transplantation reflects their underlying chronic disease state, an observation made much more frequently in patients with end-stage renal failure requiring kidney transplantation. The total numbers of hematopoietic progenitor cells, total CFU, and $\mathrm{CD} 34^{+}$cells paralleled the numbers of nucleated cells. When iliac crest was used as a

TABLE 1. Total cell yield and progenitor cell content of bone marrow obtained from different sources ${ }^{a}$

\begin{tabular}{|c|c|c|c|c|c|c|}
\hline \multirow{2}{*}{ Marrow source } & \multicolumn{2}{|c|}{ Total nucleated cells } & \multicolumn{2}{|c|}{ Total CD34 ${ }^{+}$cells } & \multicolumn{2}{|c|}{ Total CFU } \\
\hline & $n^{b}$ & $\left(\times 10^{10}\right)$ & $n$ & $\left(\times 10^{8}\right)$ & $n$ & $\left(\times 10^{7}\right)$ \\
\hline Vertebral column ${ }^{c}$ & 18 & $5.7 \pm 2.0$ & 12 & $14.0 \pm 12.0$ & 15 & $5.9 \pm 4.3$ \\
\hline Iliac crest-ALLO ${ }^{d}$ & 24 & $3.2 \pm 0.9$ & 20 & $2.7 \pm 2.2$ & 21 & $2.4 \pm 1.4$ \\
\hline Iliac crest-AUTO ${ }^{e}$ & 31 & $3.5 \pm 1.1$ & 21 & $3.1 \pm 3.1$ & 27 & $1.3 \pm 1.0$ \\
\hline Iliac crest-WO recipient ${ }^{f}$ & 24 & $1.4 \pm 0.6$ & 17 & $1.0 \pm 0.7$ & 19 & $1.3 \pm 0.9$ \\
\hline
\end{tabular}

$a$ The results are expressed as mean $\pm \mathrm{SD}$.

${ }^{b}$ Number of samples for which measurements were successful.

${ }^{c}$ Approximately 9 vertebral bodies were obtained from each VC harvested.

${ }^{d}$ Normal allogeneic marrow donor.

${ }^{e}$ Autologous marrow donor.

${ }^{f}$ Autologous harvests from recipients of whole organ allografts and donor bone marrow. 
source of BM, identical amounts of nucleated and CD34 ${ }^{+}$ cells were obtained from allogeneic donors as from autologous harvests in patients with malignancy (Table 1). The variations between the three different groups of marrow collected from iliac crests were not significant.

Hematopoietic progenitor cell assays. The concentrations of clonal hematopoietic progenitors are illustrated in Figure 1. The increased concentrations for vertebral body marrow of CFU-GM but not BFU-E and CFU-GEMM were significant at $P \leq 0.05$ when compared with the other three groups. The proportion of $\mathrm{CD}^{+} 4^{+}$cells was similarly increased for vertebral body marrow, $4.6 \pm 1.8 \%$, as compared with all iliac crest sources, $2.0 \pm 1.2 \%$ allogeneic, $3.4 \pm 4.1 \%$ autologous, and $2.8 \pm 1.6 \%$ whole organ recipient. This proportional increase together with the greater nucleated cell content accounted for the substantially greater content of CFU-GM, BFU-E, and CFU-GEMM observed in the vertebral body marrow, as shown in Table 2. Qualitatively, harvests from patients with malignancy showed the poorest content of CFU-GM, BFU-E, and CFU-GEMM for comparable numbers of nucleated or $\mathrm{CD}^{+} 4^{+}$cells. Harvests from whole organ recipients showed normal CFU-GM and CFU-GEMM with increased BFU-E as compared with normal allogeneic donors. Nevertheless, total progenitors were decreased because of the lower nucleated cell yield.

Viability. The viability of vertebral body marrow cells at the time of infusion was excellent ( $91 \pm 9 \%)$, as evidenced by trypan blue dye exclusion. Furthermore, equivalent viability was also observed in marrow from VB and that from normal allogeneic donors, when tested in cell culture.

\section{DISCUSSION}

Marrow infusion as an adjunct to whole organ transplantation has been observed to promote induction of tolerance in animal models $(19,20)$. The recent use of perioperative marrow infusion at the time of whole organ grafting in man has been associated with the rapid establishment of chimerism and with in vitro evidence of decreased antidonor reactivity in mixed lymphocyte culture (6). Marrow obtained from the vertebral bodies from cadaveric donors has been utilized in these trials. While cadaveric vertebral bodies have long been proposed as a source of bone marrow suitable for transplan-

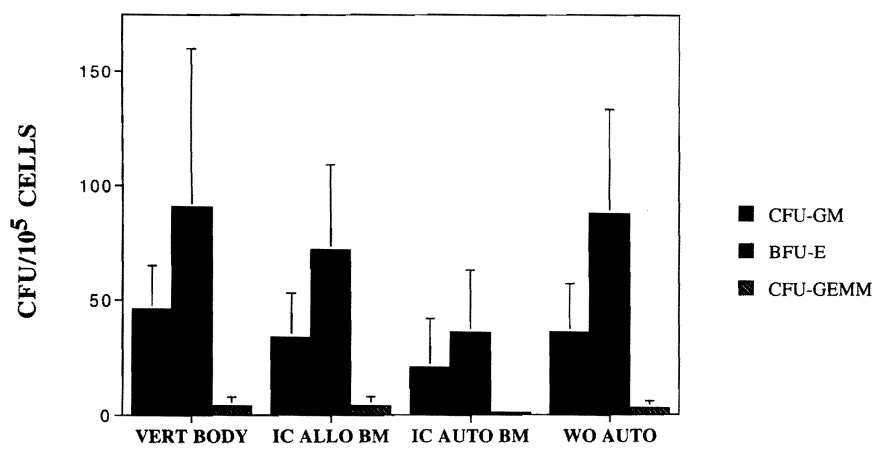

FIGURE 1. Concentration of clonal hematopoietic progenitors-CFUGM, BFU-E, and CFU-GEMM-per $10^{5}$ nucleated marrow cells in marrow from four different sources: vertebral body harvests (VERT BODY), iliac crest harvests in normal donors (IC ALLO BM), iliac crest harvests in autologous donors (IC AUTO BM), and iliac crest harvests in organ transplant recipients (WO AUTO). The mean and standard deviations are illustrated.
TABLE 2. Hematopoietic progenitor cell content of bone marrow obtained from different sources

\begin{tabular}{lcccc}
\hline & & \multicolumn{3}{c}{ Colony-forming units (CFU) $)^{a}$} \\
\cline { 3 - 5 } \multicolumn{1}{c}{ Marrow source } & $n^{b}$ & $\begin{array}{c}\text { CFU-GM } \\
\left(\times 10^{6}\right)\end{array}$ & $\begin{array}{c}\text { BFU-E } \\
\left(\times 10^{6}\right)\end{array}$ & $\begin{array}{c}\text { CFU-GEMM } \\
\left(\times 10^{5}\right)\end{array}$ \\
\hline Vertebral column $^{c}$ & 15 & $17.6 \pm 11.1$ & $39.9 \pm 34.0$ & $19.1 \pm 19.8$ \\
Iliac crest-ALLO $^{d}$ & 21 & $7.3 \pm 4.4$ & $15.6 \pm 9.6$ & $7.9 \pm 8.3$ \\
Iliac crest-AUTO $^{e}$ & 27 & $5.3 \pm 7.9$ & $8.0 \pm 6.7$ & $1.2 \pm 1.8$ \\
Iliac crest-WO recipient $^{f}$ & 19 & $3.6 \pm 2.7$ & $8.8 \pm 6.0$ & $3.2 \pm 3.2$ \\
\hline
\end{tabular}

${ }^{a}$ Mean \pm SD.

${ }^{b}$ Number of samples for which measurements were successful.

${ }^{c}$ Approximately 9 vertebral bodies were obtained from each VC harvested.

${ }^{d}$ Normal allogeneic marrow donor.

${ }^{e}$ Autologous marrow donor.

${ }^{f}$ Autologous harvests from recipients of whole organ allografts and donor bone marrow.

tation, they have rarely been used for this purpose. Our experience establishes the first large scale clinical use of this marrow source.

The techniques for excising VB and extracting BM have been described previously (9). As expected, the yields of BM cells obtained depend on the number and size of VB harvested. Lucas et al. (21) have reported an average yield of $4 \times 10^{9}$ cells/VB, an amount comparable to our own observations. The determination of the quantity of marrow that should be collected is made arbitrarily since the ultimate usage of each marrow collection depends largely on organ allocation. Since this decision is often made following organ harvesting, our aim has been to maximize our yields in each case. The determination of the quantity of marrow that should be infused in each recipient was made by matching levels that have been reported previously to achieve full hematopoietic reconstitution (10). The suitability of these criteria will have to be determined when the long-term outcome of this experience is known.

Defining the quality of marrow preparations for transplantation is a difficult task as no clear definition of the hematopoietic stem cell responsible for engraftment is available in man. The ability to engraft lethally conditioned hosts has been used as a criterion to confirm the suitability of marrow obtained from living donors (7), with recovery of hematopoiesis being used as the marker for engraftment in these patients. However, recipients of combined bone marrow and whole organs were not subjected to cytoablative or cytoreductive conditioning regimens prior to transplantation (6), therefore, recovery of hematopoiesis could not be used as a valid marker for engraftment in these patients. Furthermore, given the variable levels of chimerism achieved and high HLA disparities between the donor and the recipient, establishment of chimerism per se, cannot be used either as proof of hematopoietic engraftment or as an assessment of the quality of the marrow infused. Assays for CFU-GM, BFU-E, CFU-GEMM, and CD34 ${ }^{+}$cells have been used successfully to define autologous marrow collections $(8-11)$. We have used these assays to assess the quality of hematopoietic progenitors in marrow harvests. These assays then act as surrogate markers for the behavior of the stem cell pool contained in these collections.

By hematopoietic progenitor cell content, vertebral body marrow was superior to the standard sources. The quantities 
obtained exceeded standard sources with acceptable viability despite prolonged holding and processing times. Furthermore, the concentrations of hematopoietic progenitors in vertebral body harvests exceeded standard sources, confirming previous observations that aspirated marrow is diluted with peripheral blood. Sufficient quantities of marrow were obtained from VB to graft more than one recipient if a dose of $3 \times 10^{8}$ nucleated cells $/ \mathrm{kg}$ recipient body weight is used. Thus a single marrow collection could support multiple recipients. These findings indicate that vertebral body marrow is a clinically valuable source of marrow for transplantation.

Acknowledgments. We wish to acknowledge E. Bloom, M.D., M. de Magalhaes-Silverman, M.D., F. Dodson, M.D., J. Lister, M.D., and S. Pincus, M.D., Ph.D., for harvesting bone marrow; C. Vasko and T. Seskey for vertebral body processing; A. Houston, J. Keane, J. Mierski, and R. Roscoe for performing the in vitro assays; $K$. Sachs and A. Tambourine for typing the manuscript, and J. Harnaha for her expert copyediting of the of the manuscript. In addition, we extend special thanks to Brian Broznick, Director, Center for Organ Recovery and Education.

\section{REFERENCES}

1. Starzl TE, Demetris AJ, Trucco M, et al. Cell migration and chimerism after whole organ transplantation: the basis of graft acceptance. Hepatology 1993; 17: 1127.

2. Starzl TE, Demetris AJ, Murase N, et al. Cell chimerism permitted by immunosuppressive drugs is the basis of organ transplant acceptance and tolerance. Immunol Today 1993; 14: 326.

3. Starzl TE, Demetris AJ, Trucco M, et al. Chimerism and donor specific nonreactivity 27 to 29 years after kidney allotransplantation. Transplantation 1993; 55: 1272.

4. Starzl TE, Demetris AJ, Murase N, et al. Cell migration, chimerism, and graft acceptance. Lancet 1992; 339: 1579.

5. Starzl TE, Demetris AJ, Trucco M, et al. Systemic chimerism in human female recipients of male livers. Lancet 1992; 340: 876.

6. Fontes PA, Rao As, Demetris AJ, et al. Augmentation with bone marrow of donor leukocyte migration for kidney, liver, heart, and pancreas islet transplantation. Lancet (in press).

7. Thomas ED, Storb R. Technique for human marrow grafting. Blood 1970; 36: 507.

8. Ray RN, Cassell M, Chaplin H. A new method for preparation of human cadaver bone marrow for transfusion. Blood 1964; 17: 97.

9. Sharp TG, Sachs DH, Mathews JG. Harvest of human bone marrow directly from bone. J Immunol Methods 1984; 69: 187.

10. Storb R, Prentice R, Thomas ED. Marrow transplantation for treatment of aplastic anemia: an analysis of factors associated with graft rejection. N Engl J Med 1977; 296: 61.

11. Siena S, Bregni M, Brando B, et al. Estimation of circulating hematopoietic progenitors for autologous transplantation in cancer patients. Blood 1991; 77: 400.

12. Spitzer G, Verma D, Fisher R, et al. The myeloid progenitor cell-its value in predicting hematopoietic recovery after autologous bone marrow transplantation. Blood 1980; 55: 317.

13. Rowley S, Zuehlsdorf M, Braine H, et al. CFU-GM content of bone marrow graft correlates with time to hematologic reconstitution following autologous bone marrow transplantation with 4-hydroperoxycyclophosphamide-purged bone marrow. Blood 1987; 70: 271.

14. Ma D, Varga D, Biggs J. Donor marrow progenitors (CFU-Mix, BFU-E and CFU-GM) and haemopoietic engraftment following HLA matched sibling bone marrow transplantation. Leuk Res 1987; 11: 141.

15. Stewart F, Kaiser D, Ishitani K, et al. Progenitor cell numbers (CFU-GM, CFU-D, and CFU-Mix) and hemopoietic recovery following autologous marrow transplantation. Exp Hematol 1989; 17: 974.

16. Fontes PA, Ricordi C, Rao AS, et al. Human vertebral bodies as a source of bone marrow for cell augmentation in whole organ allografts. In Ricordi C, ed. Methods in Cell Transplantation. Austin, TX: Landes, (in press).

17. Rybka WB. Assessment of engraftment after marrow transplantation. In Ricordi C, ed. Methods in Cell Transplantation. Austin, TX: Landes (in press).

18. Roscoe RA, Rybka WB, Winkelstein A, et al. Enumeration of $\mathrm{CD}_{34}{ }^{+}$hematopoietic stem cells for reconstitution following myeloablative therapy. Cytometry 1994; 16: 74 .

19. Demetris AJ, Murase N, Fujisaki S, et al. Hematolymphoid cell trafficking, microchimerism, and GVHD reactions after liver, bone marrow, and heart transplantation. Transplant Proc 1993; 25: 3337.

20. Qian S, Demetris AJ, Murase N, et al. Murine liver allograft transplantation: tolerance and donor cell chimerism. Hepatology 1994; 19: 916.

21. Lucas PJ, Quinonas RR, Moses RD, et al. Alternative donor sources in HLA-mismatched marrow transplantation; $\mathrm{T}$ cell depletion of surgically resected cadaveric marrow. Bone Marrow Transplant 1988; 3: 211.

Received 26 May 1994.

Accepted 17 October 1994. 